\title{
Article \\ The Relationship between On-Ice and Off-Ice Performance in Elite Male Adolescent Ice Hockey Players-An Observation Study
}

\author{
Herbert Wagner ${ }^{1, * \mathbb{D}}$, Marc Abplanalp ${ }^{2}$, Serge P. von Duvillard ${ }^{1} \mathbb{D}$, Jeffrey W. Bell ${ }^{3}$, Wolfgang Taube ${ }^{2}$ and \\ Martin Keller ${ }^{4}$ (D)
}

1 Department of Sport and Exercise Science, University of Salzburg, Schlossallee 49, 5400 Hallein-Rif, Austria; spvonduvillard@aol.com

2 Department of Neuroscience and Exercise Science, University of Fribourg, 1700 Fribourg, Switzerland; dsbg@unibas.ch (M.A.); wolfgang.taube@unifr.ch (W.T.)

3 Science Department, Southwest Minnesota State University, Marshall, MN 56258, USA; jeffrey.w.bell@smsu.edu

4 Department of Sport, Exercise and Health, University of Basel, 4001 Basel, Switzerland; martin.keller@unibas.ch

* Correspondence: herbert.wagner@sbg.ac.at

Citation: Wagner, H.; Abplanalp, M. von Duvillard, S.P.; Bell, J.W.; Taube, W.; Keller, M. The Relationship between On-Ice and Off-Ice Performance in Elite Male Adolescent Ice Hockey Players-An Observation Study. Appl. Sci. 2021, 11, 2724. https://doi.org/10.3390/app11062724

Academic Editor: Redha Taiar

Received: 16 February 2021

Accepted: 16 March 2021

Published: 18 March 2021

Publisher's Note: MDPI stays neutral with regard to jurisdictional claims in published maps and institutional affiliations.

Copyright: (c) 2021 by the authors. Licensee MDPI, Basel, Switzerland. This article is an open access article distributed under the terms and conditions of the Creative Commons Attribution (CC BY) license (https:/ / creativecommons.org/licenses/by/ $4.0 /)$.
Featured Application: The presented testing concept can be applied to measure specific on-ice and off-ice performances in ice hockey that are associated with determining the improvement in ice hockey specific and general physical performance in adolescent ice hockey players.

Abstract: In elite adolescence ice hockey players, overall skating performance is an essential performance factor and should be measured adequately, whereas the relationship between on-ice and off-ice performance is not well known. Consequently, the aim of the study was to analyze (1) the differences in on-ice and off-ice performance in elite adolescent ice hockey players, and (2) the relationship between on-ice and off-ice performance in general separated into different age groups. Thirteen under-15, 18 under-17, and 19 under-20 elite male ice hockey players performed the specific overall skating performance test for ice hockey players (SOSPT). Additional tests included $30 \mathrm{~m}$ on-ice skating, off-ice skating and off-ice sprinting tests, the countermovement jump test (CMJ), the standing long jump test, the single-leg lateral jump test, and the single-leg lateral skating simulation jump test (Skate SIM). Significant differences (employing one-way ANOVA with a Bonferroni post-hoc test) between under-15, under-17, and under-20 players were found in body mass, height, leg length, CMJ height, standing long jump distance, single-leg lateral jumps from the left and right legs, Skate SIM time, off-ice sprinting time (0-6 m and 0-30 m), off-ice inline skating time $(0-30 \mathrm{~m})$, on-ice skating time (0-6 m and 0-30 m), and SOSPT time. Pearson Product-Moment correlation analysis revealed stronger correlations between SOSPT time and on-ice skating, off-ice skating, and off-ice sprinting and jump tests in the under- 15 players compared to the under-17 and under-20 players. As expected with increasing age, elite male ice hockey players performed better in on-ice and off-ice performance tests. The stronger relationship between SOSPT performance and on-ice and off-ice performance in the younger compared to the older players revealed that general physical performance determined specific overall skating performance more often in youth players, whereas in junior und young adult players, an optimal skating technique is more important. These results should be considered in the selection process for young ice hockey players.

Keywords: specific overall skating performance test; skate simulation test; sprinting; jumping

\section{Introduction}

Ice hockey is a popular contact team sport played on an ice rink, in which two teams try to score more goals than the opposing team to win the game. It is characterized by 
fast-paced intermittent offensive and defensive actions that alternate between high and low intensity movements. Teams rotate groups of players through shifts and each player will usually complete 7-8 shifts per period. During a regular $45-60 \mathrm{~s}$ shift, high intensity actions of 2.0-3.5 s occur 5-7 times. Skating on ice is a fundamental skill in ice hockey and consists of $\sim 23 \%$ gliding, $\sim 33 \%$ slow forward skating, $\sim 12 \%$ fast forward skating, $\sim 5 \%$ forward sprinting, $\sim 9 \%$ low backward skating, as well as $\sim 3 \%$ fast backward skating and sprinting in male elite ice hockey players during an official international game. Skating time with the puck contributes only $\sim 4 \%$ in elite level forwards over the course of a game. Combined with skating, ice hockey players use additional specific movements like hitting (on boards and open-ice; 15 body checks per player during a game), shooting (slap, wrist, backhand and snap; $\sim 3$ shots per player), passing (forehand, backhand, sweep, and snap; $\sim 20$ passes per player) and pass reception (forehand, backhand, or other) [1-5].

Testing on-ice skating performance is fundamental to determine the specific performance of ice hockey players. In previous studies off-ice performance (countermovement, squat, drop, hop, broad and standing long jump tests, grip strength, push-ups, sit-ups, upper body push and pull, leg press and bench press tests, different sprinting and agility tests, as well as the Wingate test, YoYo intermittent recovery, or other aerobic power tests) were analyzed to determine the relationship to hockey playing potential [6,7], draft status [8] or on-ice skating performance [9-14]. Players of higher performance levels performed better in off-ice and on-ice-tests, and there is a strong relationship between on-ice performance and several off-ice performance parameters [6-16]. However, most of these studies use forward sprint skating tests (distances ranging from 6 to $55 \mathrm{~m}$ and repeated sprint tests) to determine the on-ice skating performance in ice hockey, although forward sprinting occurs only $5 \%$ of the total time during an international game [4], and ankle motion and force production are different between forward skating and other specific skills like crossovers $[17,18]$. Only a few studies in ice hockey using tests (cornering S, repeated skate sprint, modified Reed repeat sprint skate test, cone agility, 5-10-5 pro agility and short radius turns test) including starts, stops, crossovers, and turns [9-12]. However to measure the sport specific performance, it is essential to use an on-ice test including specific movements (starting, stopping, turning, hitting, and shooting) and intensities (high, moderate, and low) that closely mimic competition to determine specific on-ice performance.

An on-ice test that is suitable to measure ice hockey specific performance is the overall skating performance test for ice hockey (SOSPT). The SOSPT was validated in a previous study [19] and found to be reliable and valid to determine the specific overall skating performance in ice hockey players. Utilizing the SOSPT in performance diagnostics enables a new perspective analyzing specific on-ice performance and should therefore increase the scientific knowledge in ice hockey. Analyzing the relationship to common used on-ice and off-ice tests will demonstrate the interaction of these tests on general and specific performance. It is also of great interest how growing ice hockey players differ in performance and if the relationship between specific and general performance is related to age. The knowledge of how young ice hockey players develop their on-ice and off-ice performance is also essential for coaches to optimize long-term training programs. However, for a practical implementation of the on-ice and off-ice performance diagnostics in the training process (especially for semiprofessional teams or in youth ice hockey), it is also essential to reduce the overall testing time and the test equipment. Consequently, we used only few tests and test equipment within one testing day.

Therefore, the aims of the study were to analyze (1) the differences in on-ice (SOSPT and on-ice skating test) and off-ice (off-ice skating and sprinting test as well as jump tests) performance in elite ice hockey players of different ages and skill levels, and (2) the relationship between on-ice and off-ice performance in general and separated by the different age groups. We hypothesized significant differences in on-ice and off-ice performance in different ages and skill levels, as well as a low relationship between the SOSPT and the on-ice skating test, off-ice skating test, and off-ice sprinting test. 


\section{Materials and Methods}

\subsection{Participants}

Thirteen under-15 (mean \pm SD; age: $13.3 \pm 0.5$ years; height: $1.62 \pm 0.1 \mathrm{~m}$; weight: $56 \pm 10 \mathrm{~kg}$, training experience $8.5 \pm 1.3$ years ( 8 forwards and 5 defensemen)); 18 under17 (mean \pm SD. age: $15.1 \pm 0.7$ years; height: $1.76 \pm 0.7 \mathrm{~m}$; weight: $68 \pm 9 \mathrm{~kg}$, training experience, $9.8 \pm 2.0$ years (10 forwards and 8 defensemen)), and 19 under-20 (mean $\pm \mathrm{SD}$ age: $17.8 \pm 0.9$ years; height: $1.78 \pm 0.05 \mathrm{~m}$; weight: $76 \pm 5 \mathrm{~kg}$, training experience $13.5 \pm 2.5$ years; ( 11 forwards and 8 defensemen)) participated in our study. All under-15, under-17, and under-20 players were recruited from the same team of the top Swiss ice hockey league of their respective age group. We included only players in the study who were training in this team at least for one year to ensure a high performance level of all participants. Four subjects of the under-15, seven subjects of the under-17, and one subject of the under-20 players were members of the Swiss National Team at the time of the study. Additionally, the goalkeepers of each team participated to enable game specific conditions during the SOSPT, but no data from the goalkeepers were measured for the subsequent evaluation or calculations.

All subjects were physically healthy and reported no injuries during the time of the study. The Institutional Review Board of the University of Salzburg approved the research protocol (GZ: 42-2015) in accordance with the Declaration of Helsinki and all subjects as well as their legal guardians reviewed and signed the informed consent prior to participation.

\subsection{Study Design}

All tests were classified as either off-ice or on-ice tests. The study was divided into two parts. In part one, all subjects performed the off-ice tests including the countermovement jump test (CMJ), the standing long jump test, the single-leg (left and right) lateral jump test, the single-leg skate simulation test (Skate SIM), the $30 \mathrm{~m}$ off-ice sprinting test, and the $30 \mathrm{~m}$ off-ice inline skating test. All off-ice tests were performed on the indoor field of the local training center. In part two, all subjects performed the $30 \mathrm{~m}$ on-ice skating test and the specific overall skating performance test for ice hockey (SOSPT) on an International Ice Hockey Federation (IIHF) conformed standard hockey rink in the local training center.

The testing procedure used a standardized testing sequence for all subjects. The testing day started by measuring anthropometric data (body height and leg length) and collecting personal data (age, playing position, and training experience). The leg length was used to standardize the Skate SIM. After preparing the equipment (glove, stick, ice skates, and inline skates) all subjects started with a general warm-up (8 min jogging) followed by a 15 min specific warm-up including mobilization, four maximal countermovement jumps and 20-30 m run-ups. Participants were divided in two randomized groups, all subjects performed the CMJ (including body weight measurement), the standing long jump test, the lateral single-leg jump test, and the Skate SIM (first group and vice versa) as well as the $30 \mathrm{~m}$ off-ice sprinting test and $30 \mathrm{~m}$ off-ice skating test (second group and vice versa). After completing the off-ice tests, all subjects returned to the ice rink (8 min jogging) and prepared for the on-ice tests. Forty minutes after finishing the off-ice tests all subjects performed a 15 min specific warm-up on-ice including forward and backward skating, ice hockey specific maneuvers such as stops, turns, and curves in all directions, as well as four $20 \mathrm{~m}$ run-ups. For the on-ice tests, all subjects first performed the $30 \mathrm{~m}$ on-ice sprinting tests followed by the SOSPT (Figure 1). All subjects performed all tests within one testing day. The subjects of the study were familiar with two intensive training sessions per day; therefore, fatigue should not have influenced performance in any tests. 


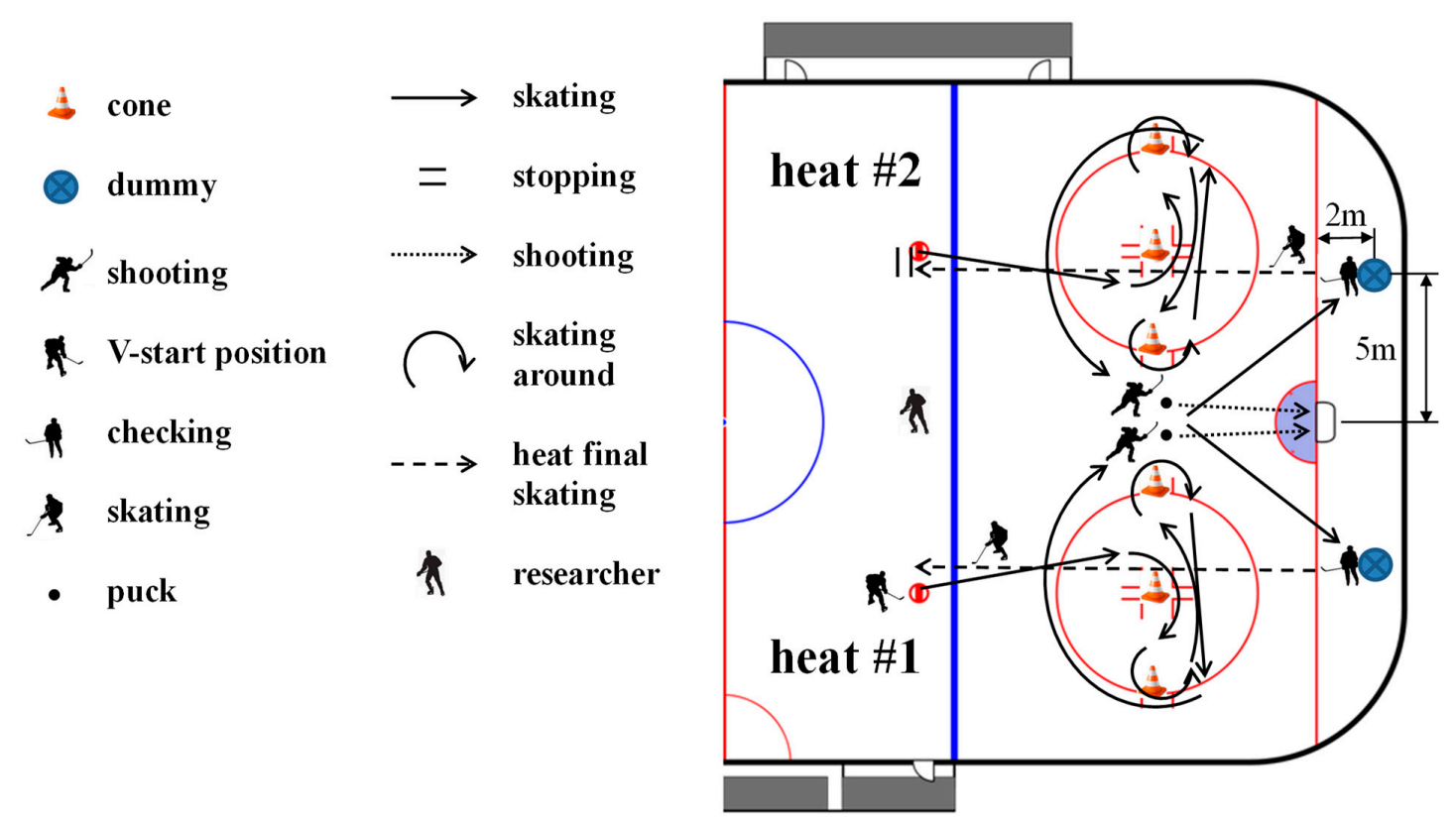

Figure 1. Schematic diagram of the specific overall skating performance test (SOSPT).

\subsection{Off-Ice Tests}

To determine vertical jump height, subjects performed three CMJs on an AMTI force platform (AMTI OR6-7, AMTI, Watertown, MA, USA) in an upright position. Arm swinging was not allowed during the jump. Jump height of the CMJ was calculated by the vertical velocity of the center of mass. Data were recorded and analyzed offline-using Matlab (Matlab2020a, MathWorks, Natick, MA, USA). The maximal value of the three repetitions ( 1 min recovery between repetitions) were utilized in calculations.

In the standing long jump test, the subjects had to stand with both feet behind the starting line (painted line) and jump as far as possible forward. Arm swing was allowed during the jump. The distance between the starting line and the last contact (heel of the rear foot) was defined as the jump distance. A jump was invalid if the subjects lost balance or touched the ground with their hands. The maximal value of the three repetitions ( $1 \mathrm{~min}$ recovery between repetitions) was used for calculations.

The single-leg lateral jump test procedure was similar to the standing long jump test. Subjects stood on one leg with the foot behind the starting line and landed on the contralateral foot. Touching the ground with the second foot was not allowed during takeoff and landing. Arm swing was allowed during the test. The maximal values of the two repetitions for each leg ( $1 \mathrm{~min}$ recovery between repetitions) were utilized in calculations.

To replicate the lateral push-off angle of on-ice skating under off-ice conditions we used the Skate SIM [20]. Two closing box parts $(1 \times 0.5 \mathrm{~m})$ were placed laterally (angle of $45^{\circ}$ to the floor) and fixed on the wall. The distance between the center of the box parts were normalized for each subject (1.5 $\times$ leg length). After an acoustic countdown (“ $3,2,1$, go") the subjects performed 20 lateral alternating single-leg jumps. A tester started timing at "go" and ended when the subject touched the box part after the 20th lateral single-leg jump utilizing a standard hand-held stop watch (Hanhart Stratos 2; Hanhart, GmbH, Gütenbach, Germany). Each subject repeated the Skate SIM twice with 2 min recovery between tests. The fastest Skate SIM time was used for calculation.

In the $30 \mathrm{~m}$ off-ice sprinting test, each subject performed a sprint as fast as possible from a standing start with their front foot one meter behind the first timing gate. The start and finish were marked with lines and the $30 \mathrm{~m}$ long and $1.5 \mathrm{~m}$ wide track was set with cones each $10 \mathrm{~m}$. To measure sprinting time, we used three light beams (Brower Timing System CM L5, Brower, UT, USA) placed at $0 \mathrm{~m}, 6 \mathrm{~m}$, and $30 \mathrm{~m}$ of the testing distance. Each 
subject repeated the sprint test twice with 2 min recovery between tests. The fastest $30 \mathrm{~m}$ sprinting time was used for calculation.

The procedure for the $30 \mathrm{~m}$ off-ice skating test was identical to the $30 \mathrm{~m}$ off-ice sprinting test. However, to familiarize them with their inline skates, all subjects performed three 20-30 m run-ups with their inline skates before the first measurement.

\subsection{On-Ice Tests}

To standardize the on-ice sprint test, a $30 \mathrm{~m}$ long and $3 \mathrm{~m}$ wide track was set with cones each $10 \mathrm{~m}$ on a regular-sized ice surface. The start and finish were marked with tripods mounted with light beams. The subjects were instructed to use a standard ice hockey V-start (front foot one meter behind the first timing gate) and skate through the finish line as fast as possible. To measure sprinting time, we used three light beams (Brower Timing System CM L5, Brower, UT, USA) placed at $0 \mathrm{~m}, 6 \mathrm{~m}$, and $30 \mathrm{~m}$ of the testing distance. Each subject completed two trials and the fastest time was used for subsequent calculation. The recovery time between the two attempts was $2 \mathrm{~min}$.

In the SOSPT, subjects performed two heats including all main skating movements and hockey specific movements (shooting and checking) on a regular-size ice hockey field, as shown in Figure 1. In heat \#1, the subjects began from a standard hockey V-start from the neutral zone faceoff spot (the rear foot was placed on the faceoff spot) and skated around a cone at the end zone faceoff spot to and around a cone placed on the lower hash mark of the goal opposite side in the end zone circle. Subsequently, the subjects skated to and around the cone placed on the lower hash mark of the goal facing side in the end zone circle and back to a cone on the lower hash mark of the goal opposite side in the end zone circle. After skating around the cone, the subjects skated around the end zone circle and shot a puck at the goal. The puck was placed one meter beside the high hash mark of the facing side in the end zone circle. The shot on goal was performed at full skating speed and the subjects skated through the goal line to the board on the left side of the goal, stopped, and simulated a body check on a dummy-placed five meters beside the midpoint of the goal and two meters below the goal line, as shown in Figure 1. Heat \#1 ended with a final skating to neutral zone faceoff spot, stopping at the spot, and directly starting heat \#2. The procedure in heat \#2 was identical to heat \#1; however, the other side of the field was used to reduce fading of the ice and to perform all movements in the opposite direction to avoid one-sidedness. The direction of skating was fixed by the test protocol as described in Figure 1 and was identical for all participants. Time was measured with a standard hand-held stopwatch (Hanhart Stratos 2, Hanhart GmbH, Gütenbach, Germany) from the subject's first movement (take-off of the rear foot) until crossing (first touch of the front foot) the neutral zone faceoff spot (start and finish). The researcher was placed between the two faceoff spots to enable a good view of the subjects (Figure 1) for determining time (start/stop) and controlling whether the subjects touched the faceoff spot between heat \#1 and heat \#2. Each subject completed one valid trial. A trial was invalid if the subjects slipped or touched a cone. If a second trial was necessary, the recovery time between the two trials was $3 \mathrm{~min}$. No subject needed more than two trials of the SOSPT. The SOSPT has been validated in a previous study [19] with high reliability $(\operatorname{ICC}(2,1)=0.92 ; \mathrm{CV}=2.44 \%)$ and validity with a strong and significant correlation between an expert rating and the SOSPT time.

\subsection{Statistical Analyses}

All statistical analyses were conducted using SPSS ver. 27 (IBM Corp., Armonk, NY, USA) with an a priori significance of $p<0.05$ for all tests. Mean values \pm standard deviations and $95 \%$ confidence intervals of the variables were calculated for descriptive statistics. Normality of the data were verified by the Shapiro-Wilk test and we found normality for all used variables. To determine the relationship between on-ice, off-ice tests and anthropometric variables (body height and weight), Pearson Product-Moment correlation coefficients were calculated. Linear regression was calculated between the 
SOSPT time and CMJ height, standing long jump height, single-leg lateral jump test, Skate SIM, off-ice sprinting, off-ice skating, and on-ice skating (0-6 $\mathrm{m}$ and $0-30 \mathrm{~m})$ for each of the age categories (under-20, under- 17 and under- 15 players). The differences in performance between under-20, under-17, and under-15 ice hockey players were determined utilizing one-way ANOVA with a Bonferroni post-hoc test.

\section{Results}

Descriptive data, mean, standard deviations $( \pm \mathrm{SD}), 95 \%$ confidence intervals, $F$ statistics, and $p$ values of the one-way ANOVA for all variables are depicted in Table 1. Significant differences between under-15, under-17, and under-20 players were found for body mass, height, leg length, $\mathrm{CMJ}$ height, standing long jump height, single-leg lateral jump from the left and right leg, skate SIM time, off-ice sprinting time $(0-6 \mathrm{~m}$ and 0 $30 \mathrm{~m})$, off-ice inline skating time $(0-30 \mathrm{~m})$, on-ice skating time $(0-6 \mathrm{~m}$ and $0-30 \mathrm{~m})$, and SOSPT time.

Table 1. Mean \pm standard deviations (SD), $95 \%$ confidence intervals (CI), F-statistics and effect sizes $\left(\eta^{2}\right)$ for the main effects of measurements.

\begin{tabular}{|c|c|c|c|c|c|c|c|c|c|c|c|c|c|}
\hline \multirow{3}{*}{ Variable } & \multicolumn{3}{|c|}{ Under-15 } & \multicolumn{3}{|c|}{ Under-17 } & \multicolumn{3}{|c|}{ Under-20 } & \multirow{3}{*}{$F$} & \multirow{3}{*}{$d f$} & \multirow{3}{*}{$p$} & \multirow{3}{*}{$\eta^{2}$} \\
\hline & \multirow{2}{*}{\multicolumn{3}{|c|}{$\begin{array}{c}\text { Mean } \pm \text { SD } \\
95 \% \text { CI }\end{array}$}} & \multirow{2}{*}{\multicolumn{3}{|c|}{$\begin{array}{c}\text { Mean } \pm \text { SD } \\
95 \% \text { CI }\end{array}$}} & \multicolumn{3}{|c|}{ Mean \pm SD } & & & & \\
\hline & & & & & & & & $\%$ & & & & & \\
\hline \multirow{2}{*}{ Body mass $[\mathrm{kg}]$} & 56.2 & \pm & 10.3 & 67.6 & \pm & 9.1 & 75.5 & \pm & 5.0 & 21.56 & 2,47 & $<0.001+\S \ddagger$ & 0.46 \\
\hline & 50.0 & - & 62.4 & 63.0 & - & 72.1 & 73.1 & - & 77.9 & 21.00 & & & \\
\hline \multirow{2}{*}{ Body height [m] } & 1.62 & \pm & 0.11 & 1.76 & \pm & 0.07 & 1.78 & \pm & 0.05 & 1968 & 247 & & \\
\hline & 1.56 & - & 1.68 & 1.72 & - & 1.79 & 1.76 & - & 1.81 & 19.68 & 2,47 & $<0.001$ is & 0.48 \\
\hline \multirow{2}{*}{ Leg length [m] } & 0.78 & \pm & 0.06 & 0.83 & \pm & 0.04 & 0.85 & \pm & 0.04 & & & & \\
\hline & 0.74 & - & 0.81 & 0.81 & - & 0.86 & 0.83 & - & 0.87 & 10.81 & 2,47 & $<0.001^{\text {ts }}$ & 0.32 \\
\hline \multirow{2}{*}{ CMJ $[\mathrm{m}]$} & 0.48 & \pm & 0.06 & 0.53 & \pm & 0.04 & 0.60 & \pm & 0.06 & & & & \\
\hline & 0.44 & - & 0.52 & 0.51 & - & 0.55 & 0.57 & - & 0.63 & 19.85 & 2,47 & $<0.001+\$ \mp$ & 0.46 \\
\hline \multirow{2}{*}{ Standing long jump [m] } & 2.11 & \pm & 0.20 & 2.33 & \pm & 0.13 & 2.50 & \pm & 0.16 & & & & \\
\hline & 1.98 & - & 2.23 & 2.27 & - & 2.40 & 2.42 & - & 2.57 & 22.69 & 2,47 & $<0.001$ 'St & 0.49 \\
\hline \multirow{2}{*}{ Single-leg lateral jump left [m] } & 2.07 & \pm & 0.15 & 2.31 & \pm & 0.15 & 2.31 & \pm & 0.15 & & & & \\
\hline & 1.98 & - & 2.16 & 2.24 & - & 2.39 & 2.22 & - & 2.40 & 10.59 & 2,47 & $<0.001^{\text {†§ }}$ & 0.31 \\
\hline \multirow{2}{*}{ Single-leg lateral jump right [m] } & 2.03 & \pm & 0.11 & 2.27 & \pm & 0.13 & 2.26 & \pm & 0.13 & & 247 & & \\
\hline & 1.97 & - & 2.10 & 2.21 & - & 2.34 & 2.20 & - & 2.32 & 15.45 & 2,47 & $<0.001$ is & 0.40 \\
\hline \multirow{2}{*}{ Lateral skate simulation test [s] } & 7.01 & \pm & 0.73 & 6.43 & \pm & 0.45 & 5.96 & \pm & 0.39 & 1596 & 247 & & 041 \\
\hline & 6.57 & - & 7.45 & 6.20 & - & 6.65 & 5.77 & - & 6.15 & 15.96 & $2,4 /$ & $<0.001$ is & 0.41 \\
\hline \multirow{2}{*}{ Off-ice sprinting $(0-6 \mathrm{~m})$ [s] } & 1.35 & \pm & 0.09 & 1.30 & \pm & 0.06 & 1.27 & \pm & 0.05 & & 2. 47 & & 019 \\
\hline & 1.30 & - & 1.41 & 1.27 & - & 1.33 & 1.25 & - & 1.30 & 5.58 & $2,4 /$ & $<0.01 \mathrm{~s}$ & 0.19 \\
\hline \multirow{2}{*}{ Off-ice sprinting $(0-30 \mathrm{~m})[\mathrm{s}]$} & 4.84 & \pm & 0.28 & 4.57 & \pm & 0.17 & 4.35 & \pm & 0.14 & & 247 & $-0001+\&+$ & 052 \\
\hline & 4.68 & - & 5.01 & 4.49 & - & 4.65 & 4.28 & - & 4.42 & 25.24 & 2,47 & $<0.001$ St & 0.52 \\
\hline \multirow{2}{*}{ Off-ice skating $(0-6 \mathrm{~m})$ [s] } & 1.45 & \pm & 0.11 & 1.45 & \pm & 0.11 & 1.37 & \pm & 0.08 & & 247 & $<005$ & 012 \\
\hline & 1.38 & - & 1.51 & 1.39 & - & 1.50 & 1.34 & - & 1.41 & 3.34 & 2,47 & $<0.05$ & 0.12 \\
\hline \multirow{2}{*}{ Off-ice skating $(0-30 \mathrm{~m})$ [s] } & 4.99 & \pm & 0.27 & 4.85 & \pm & 0.22 & 4.59 & \pm & 0.14 & & 247 & & \\
\hline & 4.82 & - & 5.16 & 4.74 & - & 4.96 & 4.52 & - & 4.66 & 15.13 & 2,47 & $<0.001$ st & 0.39 \\
\hline \multirow{2}{*}{ On-ice skating $(0-6 \mathrm{~m})$ [s] } & 1.35 & \pm & 0.10 & 1.33 & \pm & 0.08 & 1.32 & \pm & 0.06 & & & & \\
\hline & 1.28 & - & 1.40 & 1.29 & - & 1.37 & 1.29 & - & 1.35 & 0.33 & 2,47 & 0.72 & 0.01 \\
\hline \multirow{2}{*}{ On-ice skating $(0-30 \mathrm{~m})$ [s] } & 4.78 & \pm & 0.26 & 4.63 & \pm & 0.18 & 4.38 & \pm & 0.13 & & 47 & & \\
\hline & 4.62 & - & 4.93 & 4.55 & - & 4.73 & 4.32 & - & 4.45 & 18.47 & $2,4 /$ & $<0.001$ st & 0.44 \\
\hline \multirow{2}{*}{ SOSPT [s] } & 42.50 & \pm & 2.00 & 39.99 & \pm & 1.40 & 37.06 & \pm & 0.99 & 601 & 47 & $=000$ & 070 \\
\hline & 41.30 & - & 43.70 & 39.29 & - & 40.68 & 36.58 & - & 37.55 & 50.01 & 2,47 & $<0.001$ st & 0.10 \\
\hline
\end{tabular}

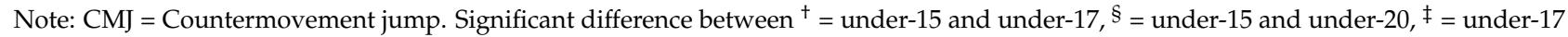
and under-20. 
Pearson Product-Moment correlation analysis revealed a significant correlation $(p<0.001)$ between SOSPT time and CMJ height $(R=-0.72)$, standing long jump height $(R=-0.81)$, single-leg lateral jump from the left $(R=-0.52)$ and right leg $(R=-0.55)$, Skate SIM $(R=0.60)$, off-ice sprinting time $0-6 \mathrm{~m}(R=0.49)$ and $0-30 \mathrm{~m}(R=0.84)$, off-ice inline skating time 0-6 $\mathrm{m}(R=0.55)$ and $0-30 \mathrm{~m}(R=0.84)$, as well as on-ice skating time $0-6 \mathrm{~m}(R=0.37)$ and $0-30 \mathrm{~m}(R=0.83)$. Linear regression plots (and calculated $\left.R^{2}\right)$ separated by age-groups of the SOSPT time and CMJ height, standing long jump height, single-leg (right and left) lateral jump distance, skate SIM, off-ice sprinting, off-ice skating, and on-ice skating (0-6 m and $0-30 \mathrm{~m}$ ) for under-15, under-17, and under-20 players are shown in Figures 2 and 3. Calculating the relationship (Pearson Product-Moment correlation) between on-ice and off-ice sprint tests, we found significant correlations $(p<0.001)$ between $(0-30 \mathrm{~m})$ off-ice sprints and off-ice skating $(R=0.75)$, as well as on-ice skating $(R=0.83)$ and between $(0-30 \mathrm{~m})$ off-ice and on-ice skating $(R=0.84)$ time.

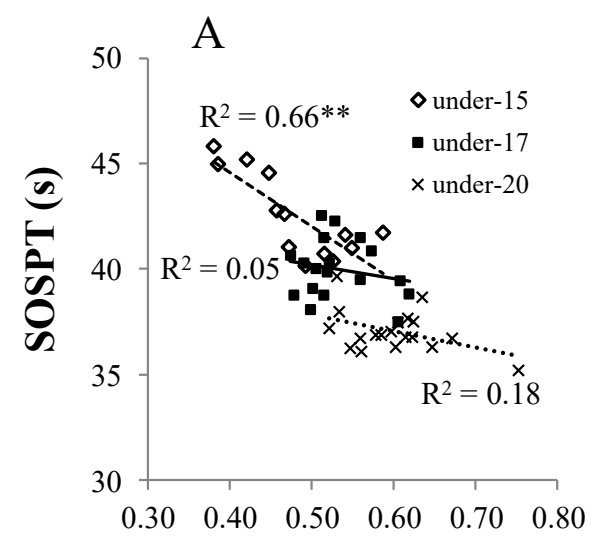

CMJ (m)

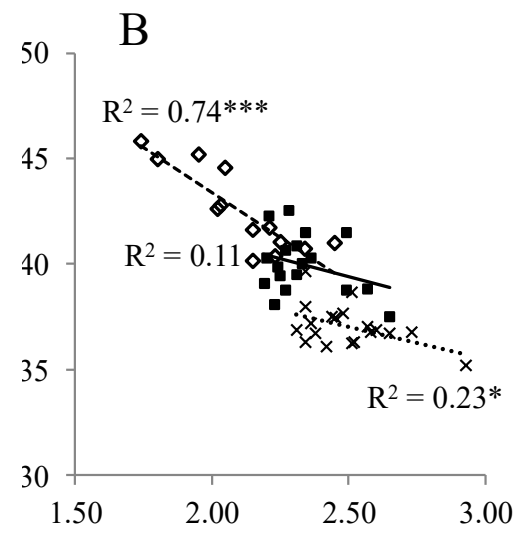

long jump test (m)

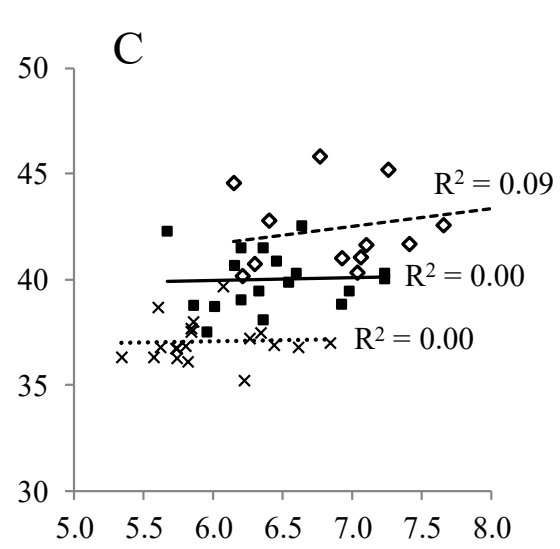

Skate SIM (s)

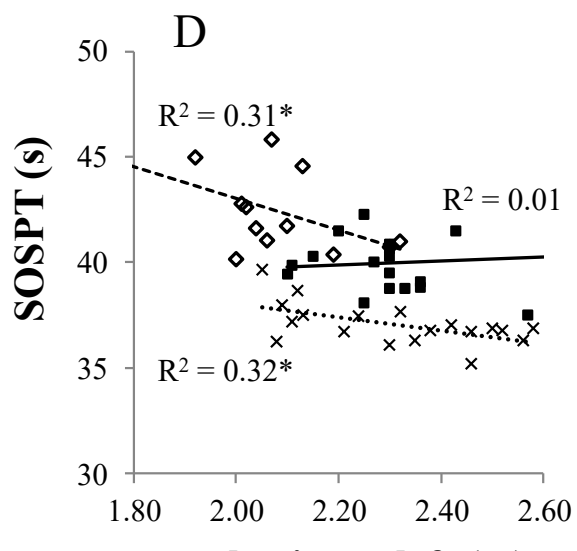

one-leg jump left (m)

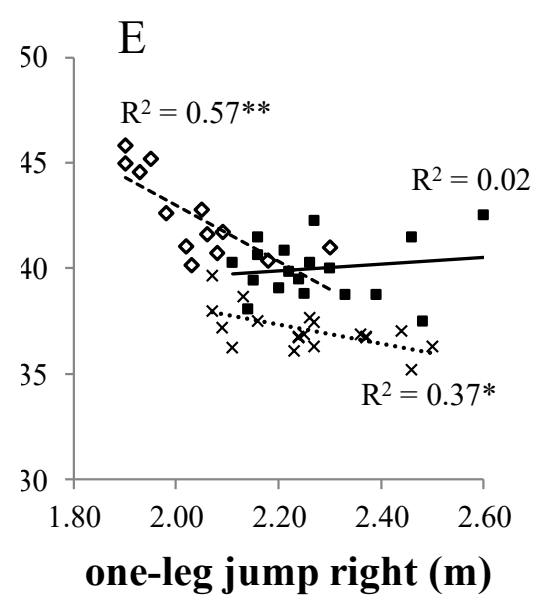

Figure 2. Linear regression analysis scatter-plot of the specific overall skating performance test (SOSPT) and (A) countermovement jump height (CMJ), (B) standing long jump distance (long jump test), (C) total time on the lateral skate simulation test (Skate SIM), (D) lateral single-leg jump left leg, and (E) lateral single-leg jump right leg separated by age groups into under-20, under-17, and under-15 players. $\left(p<0.001^{* * *} ; p<0.01^{* *} ; p<0.05^{*}\right)$. 


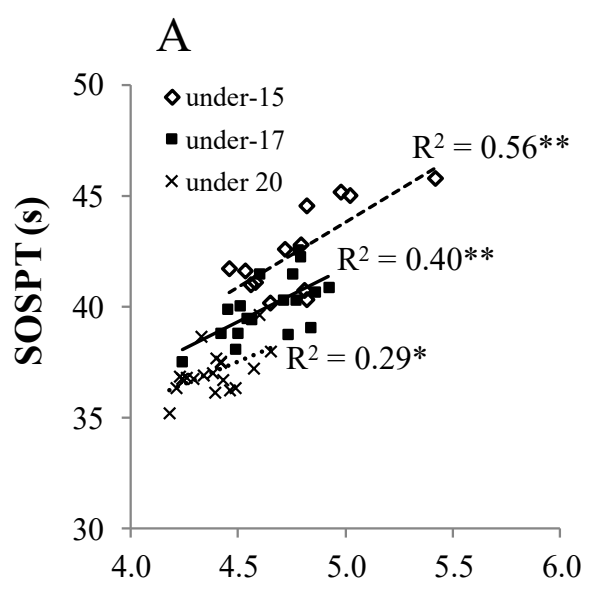

30m on-ice skating $(\mathrm{m})$
B

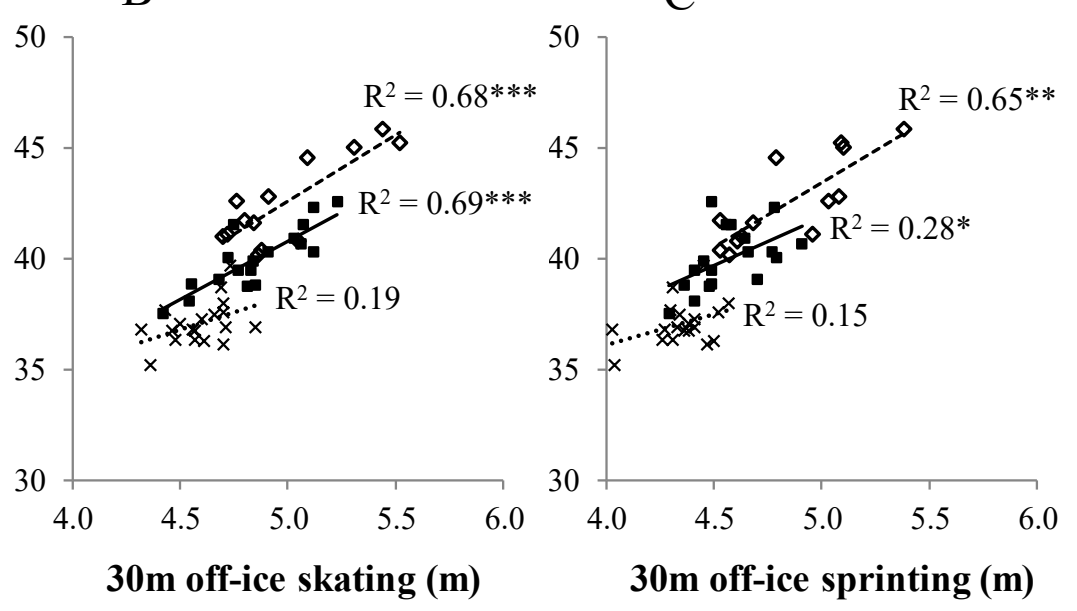

$\mathrm{E}$

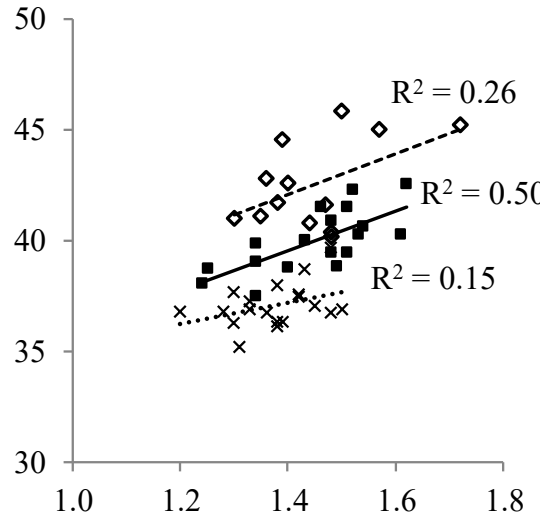

6m off-ice skating (m)
$\mathrm{F}$

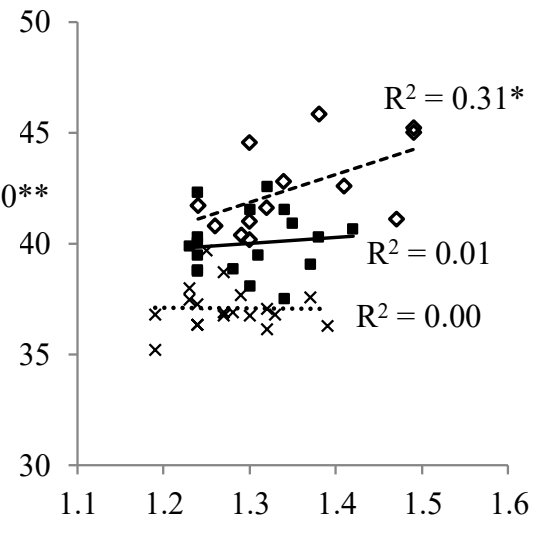

6m off-ice sprinting (m)

Figure 3. Linear regression analysis scatter-plot of the specific overall skating performance test (SOSPT) and (A) $30 \mathrm{~m}$ on-ice skating, (B) 30 m off-ice skating, (C) 30 m off-ice sprinting, (D) $6 \mathrm{~m}$ on-ice skating, (E) $6 \mathrm{~m}$ off-ice skating, and (F) $6 \mathrm{~m}$ off-ice sprinting time separated by age groups into under-20, under-17, and under-15 players. $\left(p<0.001^{* *} ; p<0.01^{* *} ; p<0.05^{*}\right)$.

\section{Discussion}

The aim of the study was to analyze the differences and relationship between on-ice and off-ice performance in elite ice hockey players of different ages and skill levels. As expected, we found significant differences in all on-ice and off-ice tests in the different age groups except for the first six meters in the $30 \mathrm{~m}$ on-ice skating test. Young adult players (under-20) are heavier and taller, jump higher, sprint, and skate faster compared to junior (under-17) and youth (under-15) elite male ice hockey players (Table 1). In previous ice hockey studies, similar results were found in on-ice and off-ice tests between different skill levels and ages [14-16]. Body height, body mass, and $30 \mathrm{~m}$ on-ice skating performance in the under-20 players in the present study (Table 1) was quite similar to those found in elite male Danish under-20 players (body height: $1.79 \pm 0.06 \mathrm{~m}$, body mass: $75.7 \pm 10.1 \mathrm{~kg}, 30 \mathrm{~m}$ on-ice skating time: $4.38 \pm 0.16 \mathrm{~s}$ ) but lower compared to elite male Finish under-20 players (body height: $1.80 \pm 0.07 \mathrm{~m}$, body mass: $78.6 \pm 8.4 \mathrm{~kg}$, $30 \mathrm{~m}$ on-ice skating time: $4.12 \pm 0.12 \mathrm{~s}$ ) [14]. The differences in skating may be due to different factors. One factor is the skating performance of the athletes. In the Ice Hockey Under-20 World Championship 2019 in Vancouver, Canada, Finland (world champion) placed higher compared to Switzerland (4th place) and Denmark (10th place). Another consideration when comparing cross-sectional data of elite athletes is the time of the 
competitive season when testing occurs. In both studies described above, the participants were tested during the preseason period; however, in the present study, the participants were tested shortly after the preseason summer training that focused more on vertical power training and less on horizontal force generation needed for fast skating. We suggest that the different training focus may have contributed to the higher CMJ height in the under-20 players of the present study (Table 1$)$ compared to the Danish $(0.39 \pm 0.04 \mathrm{~m})$ and Finish $(0.43 \pm 0.05 \mathrm{~m})$ results [14].

The best tests to discriminate $(p<0.001, F>19.0$, significant differences between every group) between the different age groups in the present study were the CMJ (vertical power), standing long jump (horizontal power), $30 \mathrm{~m}$ off-ice sprinting test, and the SOSPT. To reduce time and physical load in the testing procedures in ice hockey, we advocate using only these tests in future studies, or by sport clubs and national federations. This is due to the high correlations ( $R=0.75-0.85$ ) between the $30 \mathrm{~m}$ off-ice sprints, $30 \mathrm{~m}$ off-ice skating, and $30 \mathrm{~m}$ on-ice skating test. However, the test with the strongest results $(F=56.01)$ in the present study was the SOSPT. As depicted in Table 1, there was no overlap of the SOSPT $95 \%$ confidence intervals between the different age groups. The SOSPT can be completed in any standard hockey rink in the world and the equipment needed to complete the test such as cones, a dummy, mat, stick, and a standard hand-held stopwatch are readily available. Considering previous studies in ice hockey [6-16], the SOSPT including all specific movements (starts, stops, crossovers and turns) utilized in the on-ice tests of these studies. We propose that the SOSPT is also suitable to measure performance in the subjects of these studies. We propose utilizing the SOSPT for the selection process in clubs and federations, in addition to as a tool to monitor performance development of adolescent and adult ice hockey players of different skill levels. However, in the present study, the SOSPT was used as a single test to measure specific performance. The repetition of several SOSPT heats, including recovery breaks, may be a suitable test to measure repeated on-ice performance ability, as reported in previous studies $[10,12,15,16]$. Measuring physiological performance (blood lactate concentration, heart rate, oxygen uptake) in this repeated on-ice performance ability test may potentially determine the aerobic and anaerobic performance in ice hockey. Consequently, additional studies are warranted.

In the present study, there was a clear increase in performance with age in almost all tests. However, our cross-sectional data do not affirm any conclusions about player development, because the increase in performance may be due to two independent factors. First, long-term player development typically results in an increase in performance and, subsequently, better results can be expected in the older players. However, the higher performance by older teams could also be the results of the talent selection process. Players with a low physical performance from the under- 15 team were not recruited for the under17 team. If the newly recruited players perform better compared to the non-selected players, the selection process would also contribute to the better results in the performance tests. Consequently, longitudinal studies are warranted to analyze performance development during adolescence in ice hockey players.

The relationship between general physical performance measures and the SOSPT are shown in Figure 2. The influence of jumping performance (CMC, standing long jump, single-leg lateral jumps left and right) to the SOSPT was higher in the under- 15 compared to the under-17 and under-20 players, whereas the difference was greatest in the CMJ and long jump test. In youth, individual differences in physical performance are larger in general due to age and physical maturity status [21,22]. In the present study, the individual differences in the under- 15 players were also larger with higher standard deviations and wider $95 \%$ confidence intervals, as presented in Table 1 . We suggest that under- 15 players with a higher physical maturity status performed better, whereas under-15 players with a lower physical maturity status performed poorer in the jumping tests and SOSPT. The phenomenon of biased talent selection is well known in different team sports [23]; however, with an increasing age and the end of puberty, differences in maturation become smaller and ice hockey specific skills become more important. Stronger relationships in the under- 
15 players compared to under- 17 and under- 20 players were found between on-ice skating, off-ice skating, off-ice sprinting, and the SOSPT. In young adult male ice hockey players, the specific techniques including starts, stops, turns, crossovers, hitting, passing, and shooting determine performance; from another perspective, the general physical and forward on-ice skating performance is sufficiently trained and differences in the SOSPT are mainly determined by the specific technique. In contrast to the under-20 players, the general physical effect on-ice skating performance has more influence on the specific overall skating performance in under- 15 players. We suggest that in the under-15, compared to the under-17 and under-20 players, the vertical and horizontal power play result in a greater role in the specific on-ice overall skating performance. These results are important in the selection and training process of young ice hockey players. However, the stronger correlations in the under- 15 players compared to the under- 17 and under-20 players may also be the result of enhanced talent selection as players get older. All players were recruited from a single professional hockey team with an elite youth academy but no boarding school. Consequently, the selection of under- 15 players was limited to those who live near the training location. With increasing age, parents and youth players are more willing to travel longer distances for training under professional conditions. Consequently, under-17 and under-20 players are more homogenous and the statistical differences are reduced in these age groups. Longitudinal studies may merit in determination of the trajectory of performance development in adolescent ice hockey players.

There are also some limitations of the present study. The skate SIM was used to replicate the lateral push-off angle of on-ice skating under off-ice conditions. The subjects were instructed to complete alternating single-leg lateral jumps but the performance of these jumps by the subjects did not closely resemble the skating action. We propose not using this test in future studies or for physical tests in ice hockey. To avoid confounding factors, the SOSPT does not use a puck for skating and passing assessment because this would not permit for standardization of the test, even though these skills are important hockey performance factors. In addition, the following study only included male hockey players, although the SOSPT may also be a useful test for determining female hockey player performance abilities.

\section{Conclusions}

The aim of this study was to analyze the differences in and relationship between on-ice and off-ice performance in elite male ice hockey players of different ages and skill levels. It was found that young adult players (under-20) are heavier and taller, jump higher, sprint, and skate faster compared to junior (under-17) and youth (under-15) elite hockey players, but the SOSPT used in our study was the best test to discriminate between the different skill levels. Consequently, we recommend utilizing the SOSPT for the selection process in clubs and federations as well as a tool to determine the performance development of adolescent and adult male and female ice hockey players of different skill levels. Determining the relationship between the SOSPT and the on-ice and off-ice tests, it was found that the influence of jumping performance (CMJ, standing long jump, single-leg lateral jumps left and right), on-ice skating, off-ice skating, and sprinting performance on the SOSPT is higher in the under-15 compared to the under-17 and under-20 players. We suggest that general physical performance greatly influences specific overall skating performance in youth players, whereas in junior and young adult players, an optimal skating technique is more important. Consequently, general physical training in under- 15 players is essential for the future performance development in adolescence. For ice hockey coaches, we propose (1) a good balance between general and specific training, and (2) afford attention to the general physical performance in the selection process of young ice hockey players when recruiting new players for the team. For a professional longitudinal monitoring of elite youth, junior, and adult elite ice hockey players, we recommend utilizing the CMJ (vertical power), standing long jump (horizontal power), $30 \mathrm{~m}$ off-ice sprint test, and the SOSPT 3-4 times per year. 
Author Contributions: Conceptualization, H.W., M.K. and W.T.; methodology, H.W., M.A. and M.K.; validation, H.W., M.A. and M.K.; formal analysis, H.W. and M.K.; investigation, H.W., M.A. and M.K.; resources, M.K. and W.T.; writing-original draft preparation, H.W.; writing-review and editing, H.W., J.W.B. and S.P.v.D.; visualization, H.W., J.W.B. and S.P.v.D.; supervision, H.W. and M.K.; project administration, M.K. and W.T. All authors have read and agreed to the published version of the manuscript.

Funding: This research received no external funding.

Institutional Review Board Statement: The study was conducted according to the guidelines of the Declaration of Helsinki, and approved by the Institutional Review Board (or Ethics Committee) of the UNIVERSITY of SALZBURG (GZ: 42-2015).

Informed Consent Statement: Informed consent was obtained from all subjects involved in the study.

Data Availability Statement: The data presented in this study are available on request from the corresponding author. The data are not publicly available due to data protection rules of the University of Salzburg.

Acknowledgments: We want to thank the players and the coaches of the HC Fribourg Gotteron for participation in this study.

Conflicts of Interest: The authors declare no conflict of interest.

\section{References}

1. Bracko, M.; Fellingham, G.; Hall, L.; Fisher, A.; Cryer, W. Performance skating characteristics of professional ice hockey forwards. Sports Med. Train. Rehabil. 1998, 8, 251-263. [CrossRef]

2. Dillman, C.J.; Stockholm, A.J.; Greer, N. Movement of ice hockey players. Int. Symp. Biomech. Sports 1984, 2, 189-194.

3. Stanula, A.; Roczniok, R. Game Intensity Analysis of Elite Adolescent Ice Hockey Players. J. Hum. Kinet. 2014, 44, 211-221. [CrossRef] [PubMed]

4. Brocherie, F.; Girard, O.; Millet, G.P. Updated analysis of changes in locomotor activities across periods in an international ice hockey game. Biol. Sport 2018, 35, 261-267. [CrossRef]

5. Green, H.; Bishop, P.; Houston, M.; McKillop, R.; Norman, R.; Stothart, P. Time-motion and physiological assessments of ice hockey performance. J. Appl. Physiol. 1976, 40, 159-163. [CrossRef]

6. Burr, J.F.; Jamnik, R.K.; Baker, J.; Macpherson, A.; Gledhill, N.; McGuire, E.J. Relationship of Physical Fitness Test Results and Hockey Playing Potential in Elite-Level Ice Hockey Players. J. Strength Cond. Res. 2008, 22, 1535-1543. [CrossRef]

7. Burr, J.F.; Jamnik, V.K.; Dogra, S.; Gledhill, N. Evaluation of jump protocols to assess leg power and predict hockey playing potential. J. Strength Cond. Res. 2007, 21, 1139-1145. [CrossRef]

8. Vescovi, J.D.; Murray, T.M.; Fiala, K.A.; Van Heest, J.L. Off-Ice Performance and Draft Status of Elite Ice Hockey Players. Int. J. Sports Physiol. Perform. 2006, 1, 207-221. [CrossRef]

9. Behm, D.G.; Wahl, M.J.; Button, D.C.; Power, K.E.; Anderson, K.G. Relationship between hockey skating speed and selected performance measures. J. Strength Cond. Res. 2005, 19, 326-331. [CrossRef] [PubMed]

10. Boland, M.; Delude, K.; Miele, E.M. Relationship between Physiological Off-Ice Testing, On-Ice Skating, and Game Performance in Division I Female Ice Hockey Players. J. Strength Cond. Res. 2019, 33, 1619-1628. [CrossRef]

11. Farlinger, C.M.; Kruisselbrink, L.D.; Fowles, J.R. Relationships to skating performance in competitive hockey players. J. Strength Cond. Res. 2007, 21, 915-922. [CrossRef]

12. Janot, J.M.; Beltz, N.M.; Dalleck, L.D. Multiple Off-Ice Performance Variables Predict On-Ice Skating Performance in Male and Female Division III Ice Hockey Players. J. Sports Sci. Med. 2015, 14, 522-529.

13. Mascaro, T.; Seaver, B.L.; Swanson, L. Prediction of Skating Speed with Off-Ice Testing in Professional Hockey Players. J. Orthop. Sports Phys. Ther. 1992, 15, 92-98. [CrossRef]

14. Vigh-Larsen, J.F.; Haverinen, M.T.; Panduro, J.; Ermidis, G.; Andersen, T.B.; Overgaard, K.; Krustrup, P.; Parkkari, J.; Avela, J.; Kyröläinen, H.; et al. On-Ice and Off-Ice Fitness Profiles of Elite and U20 Male Ice Hockey Players of Two Different National Standards. J. Strength Cond. Res. 2020, 34, 3369-3376. [CrossRef] [PubMed]

15. Peterson, B.J.; Fitzgerald, J.S.; Dietz, C.C.; Ziegler, K.S.; Ingraham, S.J.; Baker, S.E.; Snyder, E.M. Division I Hockey Players Generate More Power Than Division III Players During on- and Off-Ice Performance Tests. J. Strength Cond. Res. 2015, 29, 1191-1196. [CrossRef]

16. Vigh-Larsen, J.F.; Beck, J.H.; Daasbjerg, A.; Knudsen, C.B.; Kvorning, T.; Overgaard, K.; Andersen, T.B.; Mohr, M. Fitness Characteristics of Elite and Subelite Male Ice Hockey Players: A Cross-Sectional Study. J. Strength Cond. Res. 2019, 33, 2352-2360. [CrossRef]

17. Buckeridge, E.; Le Vangie, M.C.; Stetter, B.; Nigg, S.R.; Nigg, B.M. An On-Ice Measurement Approach to Analyse the Biomechanics of Ice Hockey Skating. PLoS ONE 2015, 10, e0127324. [CrossRef] [PubMed] 
18. Robert-Lachaine, X.; Turcotte, R.A.; Dixon, P.C.; Pearsall, D.J. Impact of hockey skate design on ankle motion and force production. Sports Eng. 2012, 15, 197-206. [CrossRef]

19. Hajek, F.; Keller, M.; Taube, W.; Von Duvillard, S.P.; Bell, J.W.; Wagner, H. Testing-Specific Skating Performance in Ice Hockey. J. Strength Cond. Res. 2020. [CrossRef] [PubMed]

20. Farlinger, C.M.; Fowles, J.R. The Effect of Sequence of Skating-Specific Training on Skating Performance. Int. J. Sports Physiol. Perform. 2008, 3, 185-198. [CrossRef]

21. Bezuglov, E.; Shvets, E.; Lyubushkina, A.; Lazarev, A.; Valova, Y.; Zholinsky, A.; Waśkiewicz, Z. Relative Age Effect in Russian Elite Hockey. J. Strength Cond. Res. 2020, 34, 2522-2527. [CrossRef]

22. Moore, S.A.; Moore, M.; Klentrou, P.; Sullivan, P.; Falk, B. Maturity status in male child and adolescent athletes. J. Sports Med. Phys. Fit. 2010, 50, 486-493.

23. Baxter-Jones, A.D.G.; Barbour-Tuck, E.N.; Dale, D.; Sherar, L.B.; Knight, C.J.; Cumming, S.P.; Ferguson, L.J.; Kowalski, K.C.; Humbert, M.L. The role of growth and maturation during adolescence on team-selection and short-term sports participation. Ann. Hum. Biol. 2020, 47, 316-323. [CrossRef] [PubMed] 